\title{
PENGEMBANGAN PRODUKSI VCO (VIRGIN COCONOUT OIL) UNTUK INDUSTRI RUMAH TANGGA MELALUI SENTUHAN TTG (TEKNOLOGI TEPAT GUNA) DI DESA TONTULOW, KECAMATAN PINOGALUMAN, KABUPATEN. BOLAANG MONGONDOW UTARA, SULAWESI UTARA
}

\section{Development Of VCO Production (Virgin Coconat Oil) For HouseHold Industries Through Touch TTG (Approoriete Technology) In Tontulow Villege, Pinogaluman District, District Boolang Mongondow Utara, North Sulawesi}

\author{
Yunita Djamalu'), Evi sunarti Antu'), Max Kurniawan), Dayuwanto Harun) \\ 1, 2, )Staf Pengajar Program Studi Mesin dan Peralatan Pertanian, Politeknik Gorontalo \\ 3, 4) Mahasiswa Program Studi Mesin dan Peralatan Pertanian, Politeknik Gorontalo
}

Jl. Muchlis Rahim Desa Panggulo, Kec. Botupingge, Kab. Bone Bolango, Prov. Gorontalo

Email : naura@poligon.ac.id

\begin{abstract}
ABSTRAK
Vco (Virgin Coconout Oil) merupakan minyak kelapa yang diolah secara tradisional oleh masyarakat didesa-desa yang mempunyai aroma dan rasa yang khas dan banyak digemari masyarakat Gorontalo. Tujuan jangka panjang program ini yakni mengembangkan produksi VCO (Virgin coconout oil) dalam skala industry rumah tangga dengan menggunakan alat teknologi tepat guna. Target khusus yang ingin dicapai yakni menjadikan desa Tontulowsebagai desa pusat produksi VCO di Gorontalo. Sasaran dari program yakni masyarakat penghasil VCO dalam skala kecil yang ada di desa Tontulow Kec. Botupingge Kab. Bone Bolango. Hal ini dipertimbangkan karena lokasi desa Tontulowbanyak ditumbuhi pohon kelapa dan ada beberapa kelompok masyarakat desa Tontulowpenghasil VCO yang belum lancar dan stabil dalam memproduksi virgin coconout oil. Metode yang digunakan dalam program ini adalah pelatihan penggunaan alat Teknologi tepat guna dalam pengolahan VCO dalam skala industri rumah tangga. Untuk mendukung metode tersebut maka alur kegiatannya meliputi perancangan alat, pembuatan/fabrikasi alat, uji coba alat, serta memberikan pelatihan.
\end{abstract}

Kata Kunci : kelapa, VCO, TTG

\section{ABSTRACT}

VCO (Virgin Coconut Oil) is coconut oil that is traditionally processed by people in villages that have a distinctive aroma and taste and are much favored by the people of Gorontalo. The long-term goal of this program is to develop the production of VCO (Virgin coconut oil) in the household industry scale using appropriate technology tools. The specific target to be achieved is to make the village of Tontulows, a village center for VCO production in Gorontalo. The aim of the program is the small-scale VCO producing community in Tontulow village, Kec. Botupingge Kab. Bone Bolango. This was considered because the location of the Tontulow village was overgrown with coconut trees and there were several community groups in the village of Tontulow which produced a VCO that was not smooth and stable in producing virgin coconut oil. The method used in this program is training in the use of appropriate 
technology tools in processing VCO on a home industry scale. To support this method, the flow of activities includes designing tools, making/fabricating devices, testing tools, and providing training.

Keywords: coconut, VCO, TTG

\section{PENDAHULUAN}

Wilayah yang menjadi lokasi pelaksanaan pengabdian kepada masyarakat adalah wilayah kecamatan Pinogaluman yaitu di Desa Tontulow Kabupaten Bolaang Mongondow Utara. Kegiatan yang akan dilaksanakan adalah penyuluhan dan pelatihan cara pembuatan VCO (Virgin Coconut Oil) dengan bantuan alat TTG (Teknologi Tepat Guna). VCO (Virgin Coconut Oil) adalah minyak hasil olahan kelapa yang diolah secara tradisional dan mempunyai citra rasa dan bau yang khas saat digunakan dalam mengolah makanan, sehingga VCO ini sangat digemari masyarakat Gorontalo. Namun produksi VCO sampai saat ini masih kurang. Hal ini dapat dilihat dari sulitnya mendapatkan VCO dipasaran. Dalam pengolahan VCO, masyarakat Gorontalo masih menggunakan cara manual, yakni dengan memarut kelapa, memeras santan kelapa sampai dengan memisahkan minyak kelapa dari endapan kelapa dengan cara manual tanpa ada sentuhan teknologi. Hal ini berpengaruh pada kualitas dan kuantitas produksi VCO. Oleh karna itu dibutuhkan suatu teknologi tepat guna berupa alat pemarut dan peras yang dapat meningkatkan efisiensi kerja pada proses produksi VCO akan meningkat dan bisa dijadikan industri rumah tangga yang secara kontinyu menghasilkan VCO.

\section{Permasalahan Mitra}

Adapun permasalahan yang akan dibahas dalam kegiatan ini yakni bagaimana cara meningkatkan produksi VCO yang efektif dan efisien dalam skala rumah tangga dengan menggunakan alat teknologi tepat guna. Umumnya permasalahan yang dihadapi masyarakat dalam pengolahan VCO adalah lama proses pembuatan dan wadah yang banyak jika pengolahan dibuat manual dengan tangan manusia. Pada aktivitas penggunaan dan pembuatan VCO, Persoalan-persoalan dimaksud adalah sebagai berikut :

1. Proses yang lama, yakni dari proses pembelahan kelapa, pemarutan dan peremasan untuk menghasilkan santan kelapa

2. Membutuhkan wadah penampungan yang banyak untuk tempat kelapa parut dan santan

Proses penyaringan santan masih membutuhkan waktu lama dan kurang higienis dalam proses pembuatannya

\section{SOLUSI DAN TARGET LUARAN}

a. Solusi yang diharapkan dari permasalahan diatas adalah :

1. Adanya alat TTG (Teknologi Tepat Guna) untuk mempercepat proses pembuatan VCO

2. Hanya dibutuhkan wadah untuk santan kelapa yang dihasilkan melalui proses parut dan peras santan kelapa dengan alat TTG

3. Sudah melalui proses penyaringan otomatis

4. Higienis dalam proses peras santan kelapa karena menggunakan alat TTG yang terbuat dari stainless steel.

b. Luaran dan target capaian

Jenis luaran kegiatan :

1. Draft buku ajar

2. Rekomendasi Penggunaan dan pemanfaatan alat TTG Pemarut dan peras santan kelapa otomatis

3. Peningkatan kualitas dan kesejahteraan masyarakat Desa Tontulow 
c. Target capaian yang akan dihasilkan :

1. Menumbuhkan sikap kepedulian masyarakat desa Tontulow dalam melihat peluang usaha lain selain bertani dan berkebun untuk meningkatkan penghasilan keluarga

2. Menjadikan usaha pembuatan VCO di Desa Tontulow menjadi lebih banyak sehingga bisa menjadi desa percontohan dalam menghasilkan produk VCO yang berkuaitas.

3. Menigkatkan pengetahuan dan pemahaman masyarakat untuk cara produksi atau pun pengemasan yang baik sehingga penjualan VCO bisa relative meningkat.

4. Membangun kebersamaan warga desa dalam pembuatan alat TTG untuk proses pembuatan VCO

d. Luaran dan target capaian

Jenis luaran kegiatan :

1. Draft buku ajar

2. Rekomendasi Penggunaan dan pemanfaatan alat TTG Pemarut dan peras santan kelapa otomatis

3. Peningkatan kualitas dan kesejahteraan masyarakat Desa Tontulow

e. Target capaian yang akan dihasilkan :

1. Menumbuhkan sikap kepedulian masyarakat desa Tontulow dalam melihat peluang usaha lain selain bertani dan berkebun untuk meningkatkan penghasilan keluarga

2. Menjadikan usaha pembuatan VCO di Desa Tontulow menjadi lebih banyak sehingga bisa menjadi desa percontohan dalam menghasilkan produk VCO yang berkuaitas.

3. Menigkatkan pengetahuan dan pemahaman masyarakat untuk cara produksi ataupun pengemasan yang baik sehingga penjualan VCO bisa relative meningkat.

4. Membangun kebersamaan warga desa dalam pembuatan alat TTG untuk proses pembuatan VCO

\section{METODE PELAKSANAAN}

Gambaran Umum Masyarakat Sasaran

Desa Tontulow, Kec. Pinogaluman, Kab. Bolaang Mongondow Utara merupakan wilayah dengan tanaman kelapa yang cukup banyak. Lahan yang ditanami tanaman kelapa cukup luas, tetapi selama ini kelapa hanya diproduksi sebagai bahan baku pembuatan kopra saja. Setelah mengadakan survei tim PKM Politeknik Gorontalo memutuskan memilih masyarakat sasaran untuk program pelatihan pembuatan Virgin coconout oil adalah warga di Desa Tontulow, Kec. Pinogaluman, Kab. Bolaang Mongondow Utara. Kehidupan warga Desa Tontulow umumnya adalah Petani, namun tidak dapat meningkatkan efesien waktu dan tenaga, hanya mebercocok tanam di ladang perkebunan saja. Setelah mengkaji potensi yang ada di wilayah tersebut disepakati untuk memberikan solusi home industri untuk pembuatan virgin coconout oil. Agar masyarakat sekitar dapat melestarikannya. Dari permasalahan ini kami tim PKMberusaha memberikan solusi begitu pentingnya kelapa di daerah tersebut, agar bagaimana cara pengelolaan kelapa yang hanya terbuang percuma. Berikut gambaran masyarakat di desa Tontulow:
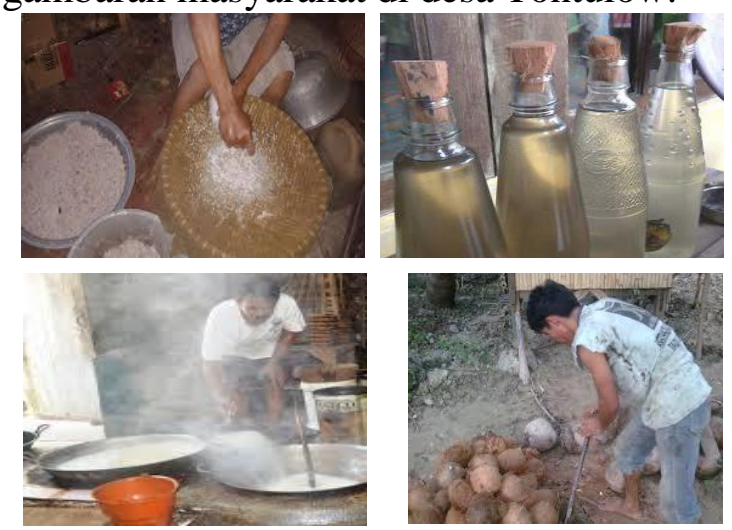

Gambar 2.1 Gambaran Umum

Pembuatan VCO secara tradisional 


\section{Metode yang akan diterapkan}

Metode yang akan dilaksanakan merupakan sebuah rangkaian tahapan yang disusun secara sistematis, berikut adalah gambaran flow map yang akan berjalan :

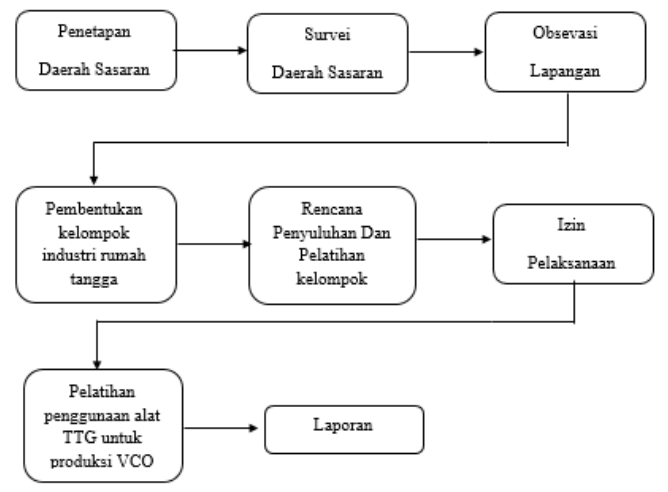

Gambar 1 Bagan Alir Pelaksanaan PkM

\section{PELAKSANAAN KEGIATAN}

Kegiatan PKM yang dilaksanakan dengan penyuluhan dengan metode ceramah tentang tata cara pembuatan dan cara kerja dari mesin parut dan peras santan kelapa untuk memudahkan proses pembuatan VCO, dilanjutkan dengan demo alat dan presentasi.

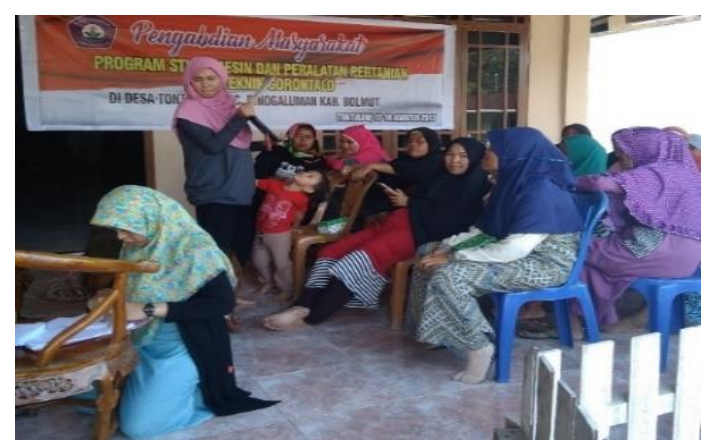

Gambar 2 Demo Alat dan Presentasi

Pelaksanan kegiatan PKM ini dibagi menjadi 2 (dua) tim. Tim yang pertama bertugas sebagai penyuluh dan tim yang kedua melaksanakan demonstrasi mesin parut dan peras santan kelapa untuk mempermudah masyarakat dalam proses pembuatan VCO Adapun teori/materi yang disampaikan saat penyuluhan yakni :

- Macam pengolahan VCO

- Pengenalan alat TTG

- Cara pembuatan Alat TTG parut dan peras santan kelapa

\section{- Cara pembuatan VCO}

Pada demonstrasi alat, cara kerja mesin parut dan peras santan kelapa dijelaskan oleh para demonstran sehingga masyarakat lebih paham dengan cara kerja mesin tersebut.

Keterbatasan waktu pertemuan mengakibatkan tidak semua masyarakat mendapat kesempatan menjalakan alat mesin parut dan peras santan kelapa

Acara kemudian dilanjutkan sesi tanya jawab. Berbagai pertanyaan diajukan secara antusias oleh para peserta dalam sesi tanya jawab secara garis besar inti dari pertanyaan para peserta adalah:

1. Berapa biaya pembuatan mesin parut dan peras santan kelapa

2. Selain mesin parut dan peras santan kelapa, mesin apalagi yang ada untuk pengolahan pasca panen hasil pertanian di Politeknik Gorontalo

3. Prospek tanaman kelapa untuk kedepan

Program pengabdian kepada masyarakat berupa pelatihan cara pembuatan dan cara kerja mesin parut dan peras santan kelapa yang sudah dilaksanakan ini diharapkan dapat menambah pengetahuan dan ketrampilan peserta tentang cara kerja mesin, selain itu dari kegiatan ini diharapkan peserta mendapatkan solusi dalam pengolahan VCO dengan alat TTG, sehingga masyarakat dapat lebih efektif dari segi waktu dalam meproses pembuatan VCO.

\section{HASIL DAN PEMBAHASAN}

Kegiatan ini dilaksanakan selama 2 hari yakni pengecekan dan proses pembelahan kelapa sampai pada proses parut dan peras santan kelapa sudah dilakukan sehari sebelum pelaksanaan pelatihan yang dilakukan pada hari Senin, tanggal 21 bulan Agustus 2017 dari pukul 09.00 s.d 16.00 wita. Peserta kegiatan berjumlah 28 orang.

Hasil kegiatan PkM secara garis besar mencakup beberapa komponen sebagai berikut: 
1. Keberhasilan target jumlah peserta pelatihan

2. Ketercapaian tujuan pelatihan

3. Ketercapaian target pelatihan yang telah direncanakan

4. Kemampuan peserta dalam mendemonstrasikan mesin parut dan peras santan kelapa

Target peserta telah memenuhi yang telah direncanakan sebelumnya. target demo alat mesin secara umum sudah baik, namun karena keterbatasan waktu pelaksanaan maka peserta tidak dapat mempraktekkan penggunaan alat dalam waktu yang lama, namun secara umum peserta sudah bisa menguasai cara mengoperasikan mesin parut dan peras santan kelapa untuk proses pengolahan VCO selanjutnya. Ketercapaian target pelatihan pada kegiatan PkM ini sudah cukup baik. karena $\mathrm{pada}$ materi telah dapat disampaikan secara keseluruhan.
Kemampuan peserta dilihat saat melakukan demonstrasi alat serta saat diberikan waktu untuk tanya jawab. Ketertarikan peserta dengan alat teknologi tepat guna yang diberikan pada kegiatan ini begitu terlihat dengan antusias mereka pada saat mendemokan alat.

Diharapkan setelah pelatihan ini para peserta akan menggunakan mesin parut dan peras santan kelapa untuk proses pembuatan VCO selanjutnya untuk dipasarkan oleh masyarakat, sehingga pengolahan kelapa menjadi VCO lebih efisien dari segi waktu.

\section{DAFTAR PUSTAKA}

Ulil Amri. Pengaruh Teknik Modeling Terhadap Ketrampilan Pembuatan Virgin Coconat Oil (VCO), EJUPEKhu Vol. 1 No. 1 Maret 2015 